\title{
Dietary protein:lipid ratio and lipid nature affects fatty acid absorption and metabolism in a teleost larva
}

\author{
Sofia Morais ${ }^{1}$, William Koven ${ }^{2}$, Ivar Rønnestad ${ }^{3}$, Maria Teresa Dinis ${ }^{1}$ and Luís E. C. Conceição ${ }^{1}$ \\ ${ }^{1}$ CCMAR, Universidade do Algarve, Campus de Gambelas, 8005-139 Faro, Portugal \\ ${ }^{2}$ Israel Oceanographic and Limnological Research, The National Centre for Mariculture, PO Box 1212, Eilat 88 112, Israel \\ ${ }^{3}$ Department of Biology, University of Bergen, Allégt 41, N-5007 Bergen, Norway
}

(Received 16 July 2004 - Revised 3 November 2004 - Accepted 19 November 2004)

\begin{abstract}
Studies with teleost larvae have reported poor performance associated with quantitative lipid imbalances in the diet. The present study examined the effect of dietary protein:neutral lipid ratio on fatty acid (FA) absorption efficiency and metabolism in larval Senegalese sole. In addition, the effect of lipid class (triolein (TRI) and L-3-phosphatidylcholine-1,2-di-oleoyl (PC)), carbon number and degree of saturation of the labelled NEFA, stearic acid (SA), oleic acid (OA) and DHA) was tested. FA absorption was determined by tube feeding $\left[1-{ }^{14} \mathrm{C}\right]$-labelled lipids and NEFA after a single meal of either non-enriched Artemia (NEA) or Artemia enriched on a soyabean oil emulsion (EA), or after feeding these diets over an extended period of time (18d). The tested dietary protein:lipid ratios had no short-term influence but long-term feeding of a diet higher in neutral lipid (EA) increased lipid accumulation within the gut epithelium and resulted in lower FA absorption (higher label evacuation and lower retention of dietary FA), which may partially explain the trend for lower growth observed with this diet. The lipids and NEFA, showed different digestive and metabolic properties, independent of feeding regime. FA absorption increased with unsaturation, being lowest for SA, followed by OA, and highest for DHA. In addition, sole larvae had a lower capacity to digest and absorb FA esterified to TRI, compared with PC, with the order of decreasing absorption being NEFA $>$ PC $\gg$ TRI. Moreover, larvae appeared to discriminate between the source of OA, as this FA in the free form or esterified to PC was catabolised less than TRI.
\end{abstract}

Solea senegalensis: Fish larvae: Lipid class: Fatty acid saturation

Lipids are an important source of metabolic energy, components of biological membranes and precursors of essential metabolites (Sargent et al. 1989). These properties are of particular importance in larval teleost fish, which are characterised by extremely high growth rates coupled with high demands for energy and structural components (Conceição, 1997). The importance of lipids in marine larval nutrition has made them the focus of numerous studies, the majority of which have been concerned with the requirements for essential fatty acids (EFA; Watanabe et al. 1983; Sargent et al. 1997, 1999). In Senegalese sole (Solea senegalensis Kaup 1858), the species studied in the present work, a few studies have investigated the qualitative fatty acid (FA) requirements of its larvae (Vásquez et al. 1994; Mourente \& Vásquez, 1996; Morais et al. 2004). However, relatively few studies have examined the impact of dietary quantitative lipid supply on larval digestion and absorption.

In the marine environment, the total lipid in phytoplankton and zooplankton in spring is approximately $20 \%$ of dry weight (DW), which is mostly composed of phospholipids (PL; Sargent et al. 1989). As these PL usually contain $50 \% n-3$ PUFA, it is estimated that the larva's natural dietary PUFA level is about $10 \%$ of diet DW (Sargent et al. 1989). In aquaculture, however, the common source of dietary $n-3$ PUFA for larval diets is triacylglycerols (TAG), which seldom have $n$-3 PUFA concentrations greater than $30 \%$. Therefore, to produce a diet resembling the larva's natural food, i.e. containing $10 \%$ of its weight as $n$-3 PUFA, at least $30 \%$ of TAG would need to be included (Sargent et al. 1989). This means that the levels of neutral lipid used to satisfy the EFA requirements might be excessive. Such a quantitative imbalance in dietary lipids may have undesirable consequences during the digestive and absorptive process and thus be detrimental to larval growth and performance.

Hoehne (1999) and Olsen et al. (2000) indicated that a high lipid level might lead to lower larval digestion ability. On the other hand, Kjørsvik et al. (1991) reported an overload of the digestive capacity in the hindgut of turbot larvae fed rotifers with a high lipid content. High content of dietary neutral lipid has been associated with the accumulation of large lipid droplets in the enterocytes of carp, gilthead seabream larvae, arctic char and rainbow trout (Díaz et al. 1997; Fontagné et al. 1998; Olsen et al. 1999; Salhi et al. 1999; Caballero et al. 2002, 2003), possibly reducing the lipid transport rate across the intestinal epithelium.

\footnotetext{
Abbreviations: AH, after hatching; DW, dry weight; EFA, essential fatty acids; EA, Artemia enriched on a soyabean oil emulsion; FA, fatty acids; NEA, non-enriched Artemia OA, oleic acid; PC, L-3-phosphatidylcholine-1,2-di-oleoyl; PL, phospholipids; SA, stearic acid; TAG, triacylglycerols; TL, total length; TRI, triolein; WW, wet weight. *Corresponding author: Dr Sofia Morais, fax +351 289818 353, email smorais@ualg.pt
} 
The present study examined changes in the FA absorption capacity and metabolism of larvae of the teleost Senegalese sole, in response to feeding a single meal having a high (non-enriched Artemia, NEA) or a low (Artemia enriched on a soyabean oil emulsion, EA) protein:lipid ratio, and after feeding these dietary regimes over an extended period of time. In addition, the effect of supplying FA esterified to a neutral or polar lipid class or in NEFA form, differing in chain length and degree of saturation, was also investigated.

\section{Materials and methods}

\section{Larval rearing and diets}

Senegalese sole ( $S$. senegalensis) eggs were obtained from naturally spawning, wild-caught broodstock maintained at the University of Algarve. Larvae were reared in 70-litre cylindrical conical tanks, in a recirculating system, at a temperature of $21 \pm 1^{\circ} \mathrm{C}$ and a salinity of $35 \mathrm{~g} / \mathrm{l}$, until settlement. At mouth opening $(2 \mathrm{~d}$ after hatching, AH), larvae were fed on Artemia AF (INVE Aquaculture NV, Dendermonde, Belgium) nauplii until $9 \mathrm{DAH}$, when Artemia EG (INVE Aquaculture NV) metanauplii enriched on Algamac-2000 (Aquafauna Bio-Marine Inc., Hawthorne, CA, USA) were then fed. At 14 DAH, frozen enriched metanauplii were introduced and replaced live Artemia. A transition period of $3 \mathrm{~d}$ was used between each prey type. When most larvae had settled at the bottom of the tank (16 DAH) they were transferred to 3-litre flat-bottomed trays (200 larvae/tray) and were fed solely on frozen Artemia EG metanauplii until the end of the experiment (34 DAH). In the short-term trial, larvae were fed on frozen metanauplii enriched on Algamac-2000, whereas in the long-term trial one larval group was fed frozen metanauplii enriched on a soyabean oil emulsion (EA) while the other group was fed frozen nonenriched Artemia (NEA). Each treatment was tested in triplicate trays and larvae were fed in excess three times daily.

A single batch of NEA and of EA was prepared at the start of each trial and was kept frozen for the trial duration. The EA treatment was prepared by enriching Artemia on a soyabean oil emulsion containing (per $100 \mathrm{~g}$ emulsion): $86 \mathrm{~g}$ commercial soyabean oil (OliSoja; Sovena, Barreiro, Portugal), $5 \mathrm{~g}$ soyabean lecithin (Sorgal, Portugal), $3 \mathrm{~g}$ Tween 80 (Sigma-Aldrich, St. Louis, MO, USA), $2 \mathrm{~g}$ alginic acid (Sigma-Aldrich), $2 \mathrm{~g}$ vitamin mixture containing $35 \%$ vitamin $\mathrm{C}$ (Sorgal) and $2 \mathrm{~g}$ mixture including $50 \%$ vitamin $\mathrm{E}$ (Sorgal). After mixing the ingredients well, the enrichment was prepared by blending the emulsion with water ( $1 \mathrm{~g}$ emulsion/100-200 g water) in a high-speed blender. Artemia were hatched according to Van Stappen (1996) and at instar II were enriched in 100-litre cylindrical conical tanks, at a density of 150 nauplii $/ \mathrm{ml}$ seawater $(35 \mathrm{~g} / \mathrm{l})$, at $28^{\circ} \mathrm{C}$ and with strong aeration. Soyabean oil enrichment was conducted over a period of $16 \mathrm{~h}$, with two doses of $0.3 \mathrm{~g}$ emulsion/l being added at 0 and $8 \mathrm{~h}$ after the start of enrichment. For the enrichment with Algamac-2000 in the short-term trial, manufacturer's instructions were followed. The NEA was prepared in the same manner, only without the addition of an enrichment emulsion.

\section{Tube feeding}

Two tube feeding trials were performed: a short-term trial examined the immediate effect of protein:lipid ratio on lipid and NEFA absorption and metabolism, while a long-term trial tested this effect over an extended period of time (18d). Both trials used five mixtures based on soyabean oil, which differed according to the ${ }^{14} \mathrm{C}$-labelled lipids that were added. Two treatments tested the effect of lipid class, where $\left[{ }^{14} \mathrm{C}\right]$ oleic acid (OA) (all FA moieties) was esterified to the TAG glycerol tri $\left[1-{ }^{14} \mathrm{C}\right]$ oleate (TRI; $3.7 \mathrm{MBq} / \mathrm{ml}$ ) and the PL L-3-phosphatidylcholine-1,2-di$\left[1-{ }^{14} \mathrm{C}\right]$ oleoyl $(\mathrm{PC} ; 0.925 \mathrm{MBq} / \mathrm{ml})$. In addition, three mixtures contained one of three ${ }^{14} \mathrm{C}$-labelled NEFA differing in saturation and carbon number: $\left[1-{ }^{14} \mathrm{C}\right] \mathrm{SA}(18: 0 ; 7 \cdot 4 \mathrm{MBq} / \mathrm{ml}),\left[1-{ }^{14} \mathrm{C}\right] \mathrm{OA}$ $(18: 1 n-9 ; 3 \cdot 7 \mathrm{MBq} / \mathrm{ml})$ or $\left[1-{ }^{14} \mathrm{C}\right]$ DHA $(22: 6 n-3 ; 3 \cdot 7 \mathrm{MBq} / \mathrm{ml})$. All radiolabelled chemicals were purchased from Amersham Pharmacia Biotech UK Limited, (Little Chalfont, Bucks., UK) except for DHA (American Radiolabeled Chemicals Inc., St. Louis, MO, USA). The tube feeding mixtures were prepared by adding the labelled lipid class or NEFA to commercial soyabean oil, to obtain a specific activity of $222 \mathrm{dpm} / \mathrm{nl}$ (or $\left.3.7 \times 10^{-6} \mathrm{MBq} / \mathrm{nl}\left(1 \times 10^{-4} \mu \mathrm{Ci} / \mathrm{nl}\right)\right)$, except for PC $(111 \mathrm{dpm} /$ nl). After mixing the 'cold' and radiolabelled lipids, the solvent in which the radiolabel was dissolved was evaporated off by flushing with $\mathrm{N}_{2}$ and the mixtures were stored at $-20^{\circ} \mathrm{C}$ until use.

In the short-term trial, 34 DAH larvae (29.4 (SD 7.1) mg wet weight $(\mathrm{WW})$ ) that had been reared on the standard feeding regime (Artemia enriched with Algamac-2000) were used, while the long-term trial was performed with $32 \mathrm{DAH}$ larvae that had been fed either NEA or EA since settlement (NEA treatment, 17.8 (SD 0.8) mg WW; EA treatment, 15.0 (SD 0.3) mg WW; ten larvae/tray, pooled sample). The trials were conducted under temperature- and salinity-controlled conditions $\left(23 \pm 1^{\circ} \mathrm{C}, 35 \mathrm{~g} / \mathrm{l}\right)$ and with continuous illumination. In both trials, approximately $14 \mathrm{~h}$ prior to the start of tube feeding and $30 \mathrm{~min}$ following their last feeding, larvae were transferred to smaller trays and transported to the experimental room, where they were acclimatised. Each tray contained twelve larvae (four larvae from each triplicate larval rearing tray). Of these, six larvae were tube-fed one of each mixture containing the different radiolabelled lipid classes or NEFA. Thirty minutes before the start of tube feeding larvae were allowed to feed on the appropriate frozen Artemia metanauplii (6000 NEA or EA per tray), after first thawing in seawater.

A detailed description of the experimental set-up for in vivo tube feeding, assimilation and metabolic studies in larval fish is given by Rønnestad et al. (2001). The larvae were tube-fed with a plastic capillary ( $0.19 \mathrm{~mm}$ inner diameter; Sigma-Aldrich), which deposited the mixture $(23 \mathrm{ml})$ in the foregut, through a nanolitre injector (World Precision Instruments, Sarasota, FL, USA). After rinsing the larvae in clean seawater for about $2 \mathrm{~min}$, they were transferred to individual $20 \mathrm{ml}$ scintillation vials (Sigma-Aldrich) containing $8 \mathrm{ml}$ fresh seawater. Each incubation vial was sealed except where a metal tube penetrating the plastic cap brought a gentle airflow to just above the incubation water, while a plastic capillary tube, through the plastic cap, connected the air above the seawater in the vial to a metabolic trap $(20 \mathrm{ml}$ vial with $5 \mathrm{ml} 0.5 \mathrm{M}-\mathrm{KOH})$. This allowed the $\mathrm{CO}_{2}$ diffused into the air of the vial with the larva to pass through the $\mathrm{KOH}$ and be retained by conversion to $\mathrm{HCO}_{3}^{-}$. After a $24 \mathrm{~h}$ incubation period each larva was washed in clean seawater and the larval gut and liver were separated from the remaining body by dissection. Body, gut and liver were placed in separate $6 \mathrm{ml}$ scintillation vials (Sarstedt, Rio de Mouro, Portugal) and solubilised in $1 \mathrm{ml}$ $30 \% \mathrm{w} / \mathrm{v} \mathrm{H}_{2} \mathrm{O}_{2}$ (Sigma-Aldrich) at $60^{\circ} \mathrm{C}$ for $24 \mathrm{~h}$, after which $4 \mathrm{ml}$ scintillation cocktail (Ultima Gold XR; Packard Bioscience, ILC Instrumentos de Laboratório e Cientificos Lda, Lisbon, Por- 
tugal) was added. After sampling the larva, the incubation vial was resealed and $1 \mathrm{ml} 0 \cdot 1 \mathrm{M}-\mathrm{HCl}$ was added in a series of gradual steps, diffusing any remaining $\mathrm{CO}_{2}$ from the water into the metabolic trap (Rønnestad et al. 2001). The incubation water and $\mathrm{KOH}-\mathrm{CO}_{2}$ (metabolic trap) were mixed with $12 \mathrm{ml}$ Ultima Gold XR. The samples were counted on a Beckman LS 6000IC (Beckman Instruments Inc., Fullerton, CA, USA) liquid scintillation counter and the results are presented as a percentage of dpm in each compartment of the total counts.

\section{Larval growth and survival}

At the end of the long-term trial (34 DAH), twenty larvae per triplicate tray were removed and their total length (TL) was individually measured. The WW of each larva was simultaneously recorded and the DW was determined individually, after freezedrying for $48 \mathrm{~h}$ in a Savant VLP120 ValuPump (Savant Instruments Inc., Hokbrook, NY, USA). The condition factor of each larva was calculated using the formula: WW (g)/[TL $(\mathrm{cm})]^{3} \times 100$. Survival was determined by counting the larvae remaining at the end of the experiments and was corrected for the individuals sampled.

\section{Artemia and larval total protein and lipid composition}

Triplicate samples of NEA and EA were collected, frozen in liquid $\mathrm{N}_{2}$ and later freeze-dried for the determination of total protein content, according to a method modified from Lowry (Rutter, 1967), and total lipid content, using the procedure of Bligh \& Dyer (1959) modified for small samples (Rainuzzo et al. 1994). The same methods were used for the quantification of total protein and lipid content of larvae submitted to the NEA and EA treatments. The assayed larvae were the same used in the determination of the individual DW, after pooling the twenty larvae from each replicate, rehydration and homogenisation (Ultra Turrax T25; IKA Labortechnik, Staufen, Germany) followed by freezedrying. Each freeze-dried sample was then divided into triplicate aliquots on which the analyses were performed. Results are presented as a percentage of sample DW.

\section{Histological analysis}

At the end of the long-term trial (34 DAH), four larvae per tray were sampled and immediately fixed in formol-calcium (4\% (v/ v) formaldehyde in $0 \cdot 1 \mathrm{M}$-calcium acetate) for about $60 \mathrm{~h}$. After dehydration, the larvae were imbedded in historesin (Leica Microsystems, Lisbon, Portugal), $2 \mu \mathrm{m}$ sections were cut in a microtome (Microm HM $340 \mathrm{E}$; Microm International $\mathrm{GmbH}$, Walldorf, Germany) and then stained with toluidine blue. Histological sections of two larvae from each replicate tray (six per treatment) were examined under an optical microscope. Observation of the slides focused on the appearance of the midgut intestinal wall.

\section{Statistical analysis}

Results are given as mean values and standard deviations and were compared by a two-way ANOVA, in which the analysed factors were 'Artemia diet' (two levels: NEA and EA) and 'tube fed label' (five levels: TRI, PC, OA, SA and DHA). Data from larval growth, survival, total protein and lipid content were analysed by
Table 1. Growth and survival of larvae fed non-enriched Artemia (NEA) and Artemia enriched on a soyabean oil emulsion (EA), at the end of the longterm trial (34 d after hatching)

(Mean values and standard deviations for sixty larvae per treatment for growth results or three trays per treatment for survival rate)

\begin{tabular}{lccccc}
\hline & \multicolumn{2}{c}{ NEA } & & \multicolumn{2}{c}{ EA } \\
\cline { 2 - 3 } \cline { 5 - 6 } & Mean & SD & & Mean & SD \\
\hline Total length $(\mathrm{mm})$ & 13.4 & 2.1 & 13.1 & 1.7 \\
Wet weight $(\mathrm{mg})$ & 21.7 & 9.3 & 19.5 & 6.3 \\
Dry weight $(\mathrm{mg})$ & 4.0 & 1.9 & & 3.6 & 1.2 \\
Condition factor & 0.85 & 0.11 & & 0.85 & 0.09 \\
Survival rate $(\%)$ & 82.8 & 3.1 & 70.5 & 14.9 \\
\hline
\end{tabular}

a one-way ANOVA. All percentage data were $\arcsin \left(x^{1 / 2}\right)$-transformed. The assumption of homogeneity of variance was checked using the Bartlett test and, for the tube feeding tests, transformations (either $1-\ln (x)$ or $\mathrm{e}^{(x)}$ ) had to be performed in some cases (Zar, 1996). When significant differences were found at the $P<0.05$ level, the Tukey HSD multiple-range test was performed (Zar, 1996) using the software Statistica 6 (StatSoft Inc., Tulsa, OK, USA).

\section{Results}

\section{Larval growth and survival}

In spite of the minor trend of increased growth performance (WW and DW) of larvae fed the lower lipid diet, no significant differences were found in growth and condition factor between the NEA or EA treatments at the end of the long-term trial (Table 1). Survival was high and independent of dietary treatment (Table 1).

\section{Artemia and larval total protein and lipid composition}

As expected, NEA showed a higher protein:lipid ratio than EA (Table 2), as the result of the similar or slightly higher relative protein content and lower lipid level than found in EA. No

Table 2. Total protein (\% dry weight (DW)), total lipid (\% DW) and protein lipid ratio of the non-enriched Artemia (NEA) and Artemia enriched on a soyabean oil emulsion (EA) used in the short- and long-term tube feeding trials, and of larvae fed NEA and EA, at the end of the long-term trial (34 d after hatching)

(Mean values and standard deviations for three determinations)

\begin{tabular}{|c|c|c|c|c|c|}
\hline & \multicolumn{2}{|c|}{$\begin{array}{l}\text { Total protein } \\
(\% \text { DW })\end{array}$} & \multicolumn{2}{|c|}{$\begin{array}{r}\text { Total lipid } \\
(\% \text { DW) }\end{array}$} & \multirow[b]{2}{*}{ Protein:lipid } \\
\hline & Mean & SD & Mean & $\mathrm{SD}$ & \\
\hline \multicolumn{6}{|l|}{ Artemia } \\
\hline \multicolumn{6}{|c|}{ Short-term trial } \\
\hline NEA & 35.5 & $2 \cdot 8$ & $15 \cdot 1$ & 0.7 & $2 \cdot 4$ \\
\hline EA & 33.9 & 1.9 & $18 \cdot 9$ & 0.2 & 1.8 \\
\hline \multicolumn{6}{|c|}{ Long-term trial } \\
\hline NEA & $31 \cdot 7$ & 0.4 & $14 \cdot 0$ & 0.5 & $2 \cdot 3$ \\
\hline EA & $32 \cdot 3$ & 1.0 & $19 \cdot 0$ & $1 \cdot 3$ & 1.7 \\
\hline \multicolumn{6}{|l|}{ Larvae } \\
\hline NEA & 57.9 & 1.4 & 23.1 & 5.5 & 2.5 \\
\hline EA & $57 \cdot 3$ & $1 \cdot 7$ & $25 \cdot 9$ & 1.6 & $2 \cdot 2$ \\
\hline
\end{tabular}


significant differences were found between treatments in larval protein and lipid composition at the end of the long-term trial (Table 2).

\section{Histological analysis}

Observation of the histology slides revealed the presence of numerous and relatively larger vacuoles within the enterocytes of the midgut region of 34 DAH larvae fed EA during the long-term trial (Fig. 1(B)). In larvae fed NEA (Fig. 1(A)), the vacuoles were smaller and the enterocytes showed a denser appearance.

\section{Absorption and metabolism of tube fed lipids and NEFA}

Two-way ANOVA of the data obtained $24 \mathrm{~h}$ after tube feeding Senegalese sole larvae with a series of labelled lipid classes (where OA is the actual tracer) and NEFA, after a single meal of either NEA or EA (short-term trial), revealed that the single meal Artemia treatments had no significant effect on absorption of the tube fed labels. However, significant differences $(P<0 \cdot 05)$ were found between the tube fed labels (Fig. 2(A)). In the water compartment, representing the amount of evacuated tracer, it was noted that TRI and SA were significantly more $(P<0 \cdot 001)$ evacuated than the remaining labels. PC and OA had a similar and intermediate effect in terms of evacuation, while DHA was significantly less evacuated. TRI was significantly less and DHA significantly more $(P<0.001)$ retained in the gut compartment, while no significant differences were found for PC, OA and SA. Label retention in the body was significantly lower $(P<0.001)$ in larvae tube-fed TRI and SA, with no differences being noted between PC, OA and DHA. As for the amount of label found in the liver, it was significantly different (higher; $P<0.001$ ) only in larvae tube-fed DHA. Analysis of the counts in the metabolic trap revealed that TRI was significantly more $(P<0.001)$ catabolised, whereas DHA catabolism was significantly lower; no significant differences were found for $\mathrm{PC}, \mathrm{OA}$ and $\mathrm{SA}$.

In the long-term trial, when larvae were fed NEA or EA from 16 to $34 \mathrm{DAH}$, the tube feeding test conducted at $32 \mathrm{DAH}$ revealed that the Artemia diet had a significant effect on the absorption of the tube fed label, with significant differences being found between larvae fed NEA or EA in the water
$(P=0.032)$ and gut $(P=0.009)$ compartments (Fig. 2(B)). Larvae previously fed EA had a significantly higher evacuation of the tube fed labelled lipid classes and NEFA and, conversely, a significantly lower retention in the gut. As for the factor 'tube fed label', significant differences were also found between the tested labels, in all analysed compartments. In terms of evacuation, TRI and SA had a significantly higher $(P<0.001)$ evacuation than the remaining tracers. The lowest amount of label was found in the water of larvae tube-fed DHA, followed by $\mathrm{OA}$ and, finally, PC. Larvae tube-fed TRI and SA presented a significantly lower $(P<0.001)$ retention of label in the gut, in contrast with DHA, which induced a significantly higher (over $50 \%$ ) retention; PC and OA were not significantly different from each other, with intermediate values. The same results were obtained for the retention of label in the body $(P<0.001)$ as in the gut, although in this case OA was not significantly different from DHA. The amount of label found in the liver was significantly higher $(P<0.001)$ in larvae tube-fed the DHA label, followed by OA and SA (but SA was not significantly different from PC) and significantly lower in larvae tube-fed TRI and PC. In larvae tube-fed DHA and SA there was a significantly lower $(P<0.001)$ amount of label in the metabolic trap, whereas no significant differences were found in the catabolism of the remaining labels.

\section{Discussion}

Dietary protein:lipid ratios affect larval growth and gut histology in teleost larvae

Several studies have reported poor larval growth and performance that has been attributed to either a quantitative (lipid excess, i.e. low protein:lipid ratio) or qualitative (lipid class) imbalance of the diet (Kjørsvik et al. 1991; Hoehne, 1999; Pousão-Ferreira et al. 1999; Olsen et al. 2000). Given the importance of EFA in larval growth and survival (Watanabe et al. 1983; Sargent et al. 1997, 1999), effects caused by differences in dietary total lipid content may be masked by differences in dietary EFA level. Therefore, in order to compare a higher dietary lipid supply with a diet containing no lipid enrichment, as is the case of NEA, soyabean oil was chosen as the neutral lipid for Artemia enrichment because of its deficiency in the EFA, DHA, EPA and arachidonic acid. In the present study, despite the EFA deficiency of both NEA and EA treatments,

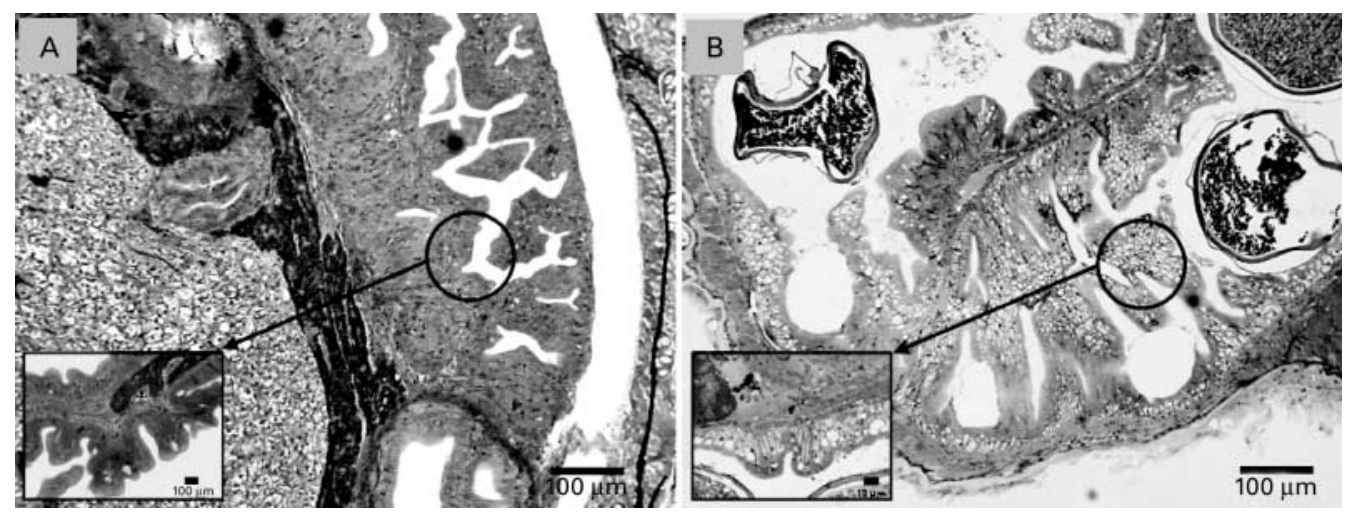

Fig. 1. Histological sections ( $2 \mu \mathrm{m}$ historesin sections stained with toluidine blue) of the midgut region of Senegalese sole larvae, $34 \mathrm{~d}$ after hatching, fed non-enriched Artemia (A) and Artemia enriched on a soyabean oil emulsion (B), at the end of the long-term trial. 
(A)
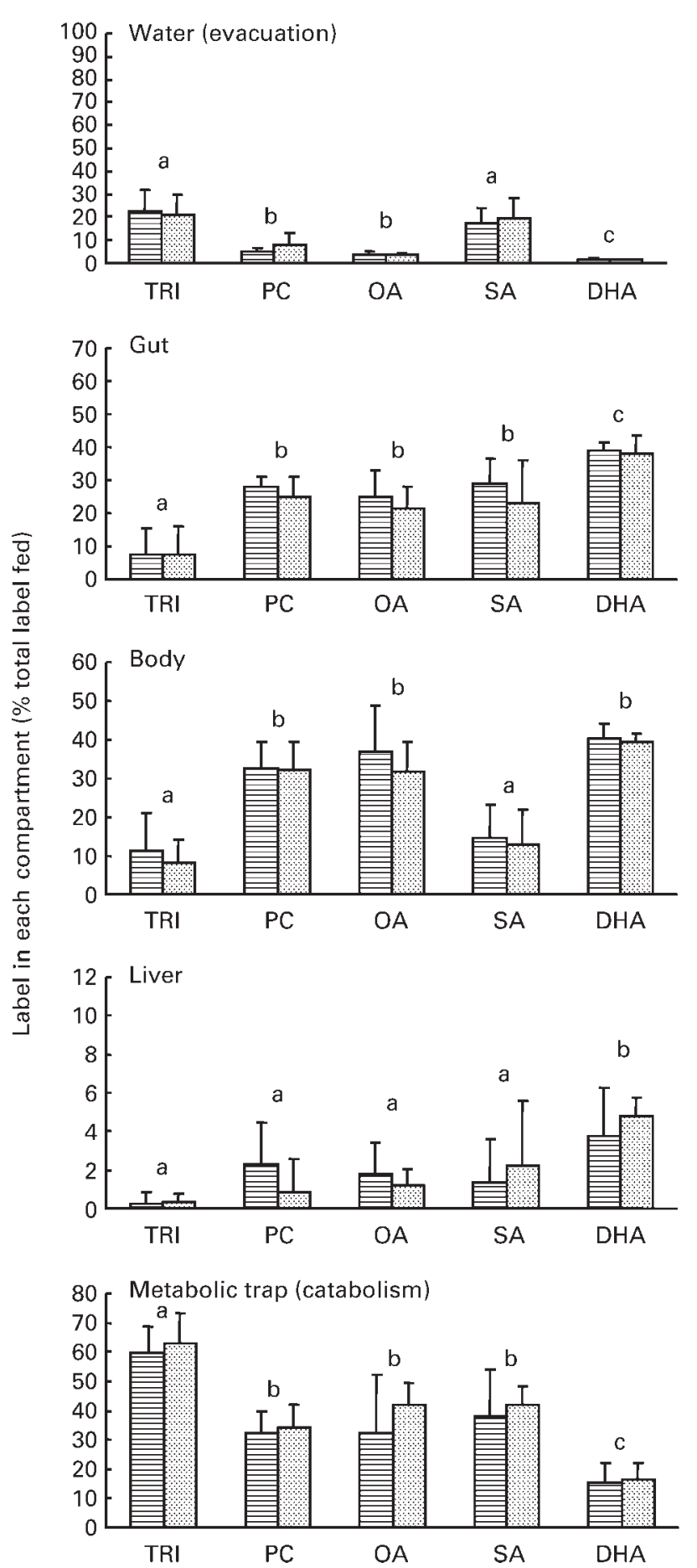

(B)
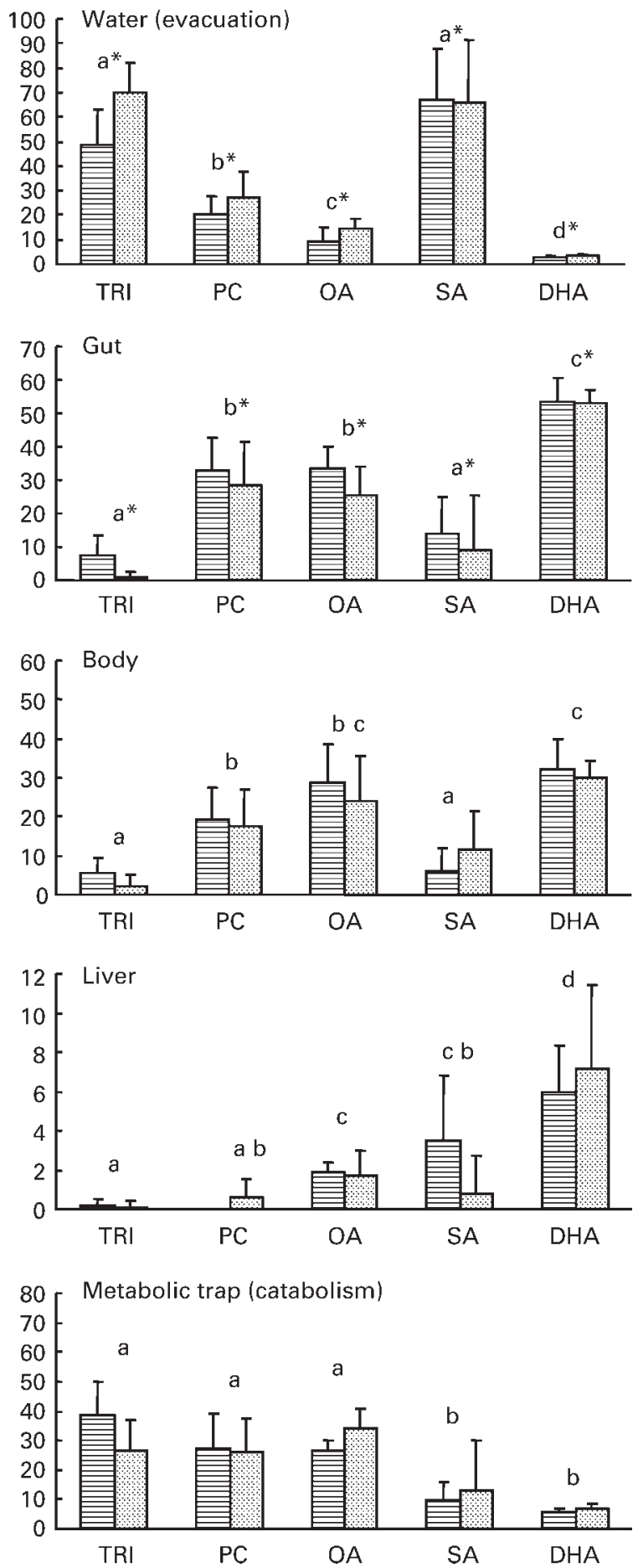

Fig. 2. Label in each compartment (\% of total tube fed label), $24 \mathrm{~h}$ after tube feeding Senegalese sole larvae with one of several ${ }^{14} \mathrm{C}$-labelled lipids and $\mathrm{NEFA}$ (TRI, triolein; PC, phosphatidylcholine-1,2-di-oleoyl; OA, oleic acid; SA, stearic acid; DHA, docosahexaenoic acid). Prior to tube feeding, larvae were fed a meal of non-enriched Artemia (NEA, 目) or Artemia enriched in soyabean oil (EA, 図). (A) Short-term trial, $34 \mathrm{~d}$ after hatching (AH); (B) long-term trial, $32 \mathrm{AH}$. Values are means with standard deviations shown by vertical bars $(n 6)$ and were analysed by a two-way ANOVA, followed by the Tukey HSD test when $P<0.05$. Tube fed labels with unlike superscript letters produced significantly different results $(P<0.05)$. Mean values were significantly different between NEA and EA in the longterm trial in the water and gut compartments $(\mathrm{B}):{ }^{*} P<0.05$.

Senegalese sole appeared to perform well, in terms of growth and survival, on these diets. Similar results were reported in a previous study using NEA (Morais et al. 2004), while Howel \& Tzoumas (1991) found good growth and survival in Solea solea larvae fed diets almost deficient in DHA. Larval weight, at the end of the long-term trial, appeared slightly higher (although not significantly different) when larvae were fed NEA rather than EA. 
No significant differences were found in larval total protein and lipid content, although lipid level tended to be higher in larvae fed EA. On the other hand, the dietary treatment did affect the histological appearance of the midgut mucosal epithelial cells. The midgut tissue of larvae fed NEA appeared dense, with small vacuoles, while the enterocytes of larvae fed EA showed a markedly higher number of larger vacuoles, most likely corresponding to lipid inclusions. It has been claimed that the transport of lipid from the enterocytes of the digestive tract into the body tissues is more problematic during larval rearing than lipid digestion per se (Izquierdo et al. 2000). Larvae fed TAG-rich diets commonly show an accumulation of lipid vacuoles in the basal zone of the enterocytes, which indicates good digestion and absorption of dietary TAG but a reduced transport capacity (Díaz et al. 1997; Fontagné et al. 1998; Olsen et al. 1999; Salhi et al. 1999; Izquierdo et al. 2000; Caballero et al. 2002, 2003). Noaillac-Depeyre \& Gas (1974) described similar lipid droplets in the enterocytes of carp, which seem to act as temporary sites of lipid storage. This is thought to be a natural occurrence in fish that results from the slow lipid processing occurring between FA absorption from the digestive tract to the secretion of lipoproteins that transport lipid in the serum to the tissues (Noaillac-Depeyre \& Gas, 1974; Sire \& Vernier, 1981). However, unbalanced diets may extend this process further. In rats, it has been shown that an increased rate of TAG infusion leads to an increased transport time from the endoplasmic reticulum to the Golgi apparatus, up to a point where saturation of TAG occurs in the endoplasmic reticulum, inhibiting further lipid transport (Mansbach \& Dowell, 2000). In some cases, these extensive lipid accumulations have been considered pathological, as they may damage enterocyte integrity and prevent normal nutrient transport (Olsen et al. 1999).

\section{Dietary protein:lipid ratios affect fatty acid absorption in teleost larvae}

In the short-term trial investigating the effect of a single meal of diets containing different protein:lipid ratios, no significant effect on lipid absorption and metabolism was observed in $34 \mathrm{DAH}$ sole larvae, although a non-significant trend, similar to that obtained during the long-term trial, was suggested. On the other hand, when these diets were fed over an extended period of time there was a significant influence on larval FA absorption efficiency. The higher dietary neutral lipid in the EA diet significantly increased the evacuation of the labelled FA and lowered its retention in the gut of larvae that were tube-fed. Moreover, there was, apart for SA, a lower non-significant FA retention in the body of larvae fed EA. These results suggest that the long-term feeding of a diet higher in neutral lipid might affect the capacity of larvae to efficiently absorb dietary FA. This may be a result of the higher accumulation of lipid droplets observed within the gastrointestinal mucosa, which may present a physical barrier to further efficient lipid absorption. In rats, it was first thought that the rate-limiting step for esterification in the intestinal mucosa was the FA absorption from the lumen. However, it was later discovered that an increase in esterification rate resulted in an increased OA flux from the lumen, which indicates that the intracellular FA pool may regulate uptake (Borgström, 1977). This also explains why, in fish larvae, a higher accumulation of lipid in the enterocytes might lead to an impaired FA absorption and increased evacuation.
Effect of lipid nature on fatty acid digestion, absorption and metabolism

The present study revealed that different labelled lipid classes and NEFA presented a specific pattern of utilisation, with significantly different effects on FA digestion, absorption and metabolism, independent of the previous feeding regimen.

The patterns of NEFA absorption and metabolism observed in the present study agree well with the work of several other authors. The absorption of FA depends on both chain length and degree of saturation, as this affects the physical properties of the molecules, namely, their water solubility and melting point, which ultimately affect the rate of diffusion in the unstirred water layer (Borgström, 1977). Thus, FA digestibility in fish is known to decrease with increasing chain length and increase with unsaturation (Austreng et al. 1979; Lie et al. 1987; Sigurgisladottir et al. 1992; Koven et al. 1994; Olsen et al. 1998; Johnsen et al. 2000; Caballero et al. 2002, 2003). In the present study, a precise calculation of total label absorption (indicative of digestibility) was not possible since some of the lipid could still be seen (during dissection) in the gut lumen $24 \mathrm{~h}$ after tube feeding and, therefore, could potentially still be evacuated. However, the evacuation results when NEFA were tube fed indicate that FA absorption efficiency was lowest for SA, followed by OA, and was highest for DHA. Only traces of DHA label were evacuated, while its retention in the body and particularly in the gut (comprising gut lumen plus gut wall) was high. However, it is likely that a major part of the DHA assigned to the gut compartment is in fact absorbed into the gut wall. In addition, DHA was only minimally catabolised for energy purposes, which agrees well with its essential and structural role (Sargent et al. 1997, 1999). The uptake of FA into the enterocyte was long thought to occur through passive diffusion but recent studies in mammals indicate that the cellular uptake of long-chain FA may be carriermediated (through a FA-binding protein located in the brush border membrane; Nordskog et al. 2001). Ockner et al. (1972) measured a higher rate of esterification of long-chain unsaturated FA than of saturated FA in rats and attributed these results to differences in the binding affinity of FA to a cytosolic FA-binding protein. The same phenomenon could explain the higher absorption of DHA in relation to OA and the lowest absorption of SA in the present study. In fish, Sire \& Vernier (1981) have suggested the presence of a transport protein with characteristics similar to the FA-binding protein found in mammals and observed a higher affinity towards PUFA. However, when looking at the uptake and esterification of radiolabelled FA by rainbow trout enterocytes, Pérez et al. (1999) reported that no significant differences were found in the rate of uptake of saturated FA, MUFA and several PUFA over a 15 min incubation period. Nevertheless, the FA distributed themselves differently between the enterocyte lipid classes and DHA was recovered in higher amounts in the polar lipid fraction, the same having been described by Caballero et al. (2003) in seabream juveniles. Also, the activity of acylCoA:1-lysophosphatidylcholine acyltransferase, the enzyme responsible for PL intestinal esterification, was higher towards arachidonoyl-CoA (a highly unsaturated fatty acid) than towards oleoyl-CoA (Poirier et al. 1997). Therefore, DHA, being more incorporated into structural lipids, may have been particularly retained within the membranes of the digestive tract mucosa.

Studies in several fish species have described that saturated FA in general and SA in particular appears very resistant to digestion 
and has a low absorption rate (Patton et al. 1977; Lie et al. 1987; Olsen et al. 1998; Røsjø et al. 2000; Caballero et al. 2002). In the present study SA was supplied as NEFA and therefore digestion was not a limiting factor affecting absorption. Nevertheless, SA was absorbed less well than the other tested FA.

Qualitative lipid imbalances of the high-lipid diets used to feed marine fish larvae have been frequently suggested as the main problem associated with these diets, caused by the lipid source being mostly TAG (Geurden et al. 1995; Fontagné et al. 1998; Olsen et al. 1999; Salhi et al. 1999; Hadas et al. 2003). Interesting observations can be made by comparing TRI, PC and OA treatments, given that OA was the labelled FA in all of them. Comparative analysis of the results revealed that the metabolic fate of OA depended on the lipid class it was esterified to or if it was supplied in a free form. Borgström (1977) showed that when $\left[1-{ }^{14} \mathrm{C}\right]$ TRI was infused into the intestine of rat instead of OA, luminal lipolysis seemed to regulate absorption rate. The same seems to apply in the present study, with the TRI label being considerably less absorbed than OA. The higher evacuation of TRI indicates that the larvae have a lower capacity to digest and absorb TAG than PL. In addition, the significantly lower amount of TRI label found in the gut $24 \mathrm{~h}$ after tube feeding (including in the NEA treatment) suggests that the lower digestive and absorptive capacity towards this TAG might be related to a more deficient emulsification and lower efficiency of neutral lipases (compared with phospholipases), rather than to a deficient absorption of the products of lipid digestion (i.e. OA).

PC and OA were metabolised by the larvae in essentially the same way, which indicates a very high efficiency of phospholipase digestion and absorption of the products of PL digestion. Compared with larvae tube-fed PC, a slightly higher amount of label was found in the metabolic trap and a lower amount in the gut of larvae tube-fed OA, $24 \mathrm{~h}$ after tube feeding. This might simply be the result of a potentially faster absorption from the gut lumen and subsequent metabolism of the NEFA. Accumulating evidence suggests that dietary PL, particularly PC, by being important components of lipoproteins, improve assimilation of dietary FA from the mucosa lining of the digestive tract into the body tissues (Geurden et al. 1995; Fontagné et al. 1998; Olsen et al. 1999; Salhi et al. 1999; Hadas et al. 2003). The role of PL as an emulsifier and enhancer of lipoprotein synthesis and FA absorption could not be directly tested in the present study, as it is unlikely that the amount of tube-fed PL had a physiological postprandial effect. There is, however, indirect evidence that this factor might have played a role, when comparing the short-term and long-term trials, even though the larvae used in the short-term trial were slightly older and larger. An obvious difference was the higher label evacuation observed in the long-term trial, independently of the tube-fed label. This might be explained by the previous dietary regimen, as both dietary treatments on the long-term trial were PL-deficient, whereas in the short-term trial larvae were reared on Artemia metanauplii enriched with Algamac-2000. This enrichment product has a higher provision of PL, as well as of PUFA, which may have boosted the endogenous pool of PL, possibly leading to a higher FA absorption. However, on the other hand, the treatments in the long-term trial, being deficient in EFA, may have also led to a lower larval nutritional condition and some degree of membrane dysfunction.

Pérez et al. (1999) and Caballero et al. (2003) noted that OA was esterified mainly into the TAG of trout and seabream enter- ocytes and its utilisation for energetic purposes in fish larvae was postulated (Pérez et al. 1999). On the other hand, results obtained by Caballero et al. (2002) suggest that OA is used less as an energy source, compared with other FA. A very interesting finding of the present study was the fact that larvae appeared to discriminate according to the lipid class OA was esterified to or if it was in a free form. OA esterified to TRI was highly catabolised, with $84-93 \%$ of the total absorbed label (not including the gut compartment) being used up for energy purposes, while OA in the free form or esterified to PC was significantly less $(P<0.05)$ catabolised $(44-58 \%$ of absorbed label). Although TAG are considered mainly an energetic source and PL have essentially a structural and functional role (Sargent et al. 1989), no compelling hypothesis can be proposed to explain this effect.

\section{Conclusions}

The results of the present study show no significant short-term (immediate) influence of the tested dietary protein:lipid ratios on the lipid digestive and absorptive capacity of Senegalese sole larvae (even though a non-significant trend was suggested). However, long-term feeding of a diet higher in neutral lipid resulted in the intracellular accumulation of larger lipid vacuoles in the larval gut mucosa, concurrently with reduced absorption efficiency of dietary FA. Furthermore, the decrease in FA absorption efficiency of larvae fed a higher neutral lipid diet (EA) may partially explain the tendency for lower growth observed when feeding this diet. In addition, the results confirmed that FA absorption increases with unsaturation. Moreover, the molecular form in which the FA was offered (NEFA, PL or TAG) affected absorption in larval Senegalese sole. This can be described in order of decreasing absorption efficiency as NEFA $>$ PC $\gg$ TAG.

\section{Acknowledgements}

Sofia Morais is the holder of a $\mathrm{PhD}$ grant from the 'Fundação para a Ciência e a Tecnologia', Portugal (SFRH/BD/4902/2001). This work benefited from funding by Project DIVERAQUA/SP5.E36 (Programme INTERREG III A, co-funded by FEDER, European Commission).

\section{References}

Austreng E, Skrede A \& Eldegard Å (1979) Effect of dietary fat source on the digestibility of fat and fatty acids in rainbow trout and mink. Acta Agric Scand 29, 119-126.

Bligh EG \& Dyer WJ (1959) A rapid method of total lipid extraction and purification. Can J Biochem Physiol 37, 911-917.

Borgström B (1977) Digestion and absorption of lipids. In International Review of Physiology, Gastrointestinal Physiology II, vol. 12, pp. 305-323 [RK Crane, editor]. Baltimore, MD: University Park Press.

Caballero MJ, Obach A, Rosenlund G, Montero D, Gisvold M \& Izquierdo MS (2002) Impact of different dietary lipid sources on growth, lipid digestibility, tissue fatty acid composition and histology of rainbow trout, Oncorhynchus mykiss. Aquaculture 214, 253-271.

Caballero MJ, Izquierdo MS, Kjørsvik E, Montero D, Socorro J, Fernández AJ \& Rosenlund G (2003) Morphological aspects of intestinal cells from gilthead seabream (Sparus aurata) fed diets containing different lipid sources. Aquaculture 225, 325-340.

Conceição LEC (1997) Growth in early stages of fishes: an explanatory model. PhD Thesis, Wageningen Agricultural University. 
Díaz JP, Guyot E, Vigier S \& Connes R (1997) First events in lipid absorption during post-embryonic development of the anterior intestine in gilt-head sea bream. J Fish Biol 51, 180-192.

Fontagné S, Geurden I, Escaffre A-M \& Bergot P (1998) Histological changes induced by dietary phospholipids in intestine and liver of common carp (Cyprinus carpio L.) larvae. Aquaculture 161, 213-223.

Geurden I, Radünz-Neto J \& Gergot P (1995) Essentiality of dietary phospholipids for carp (Cyprinus carpio L.) larvae. Aquaculture 131, 303-314.

Hadas E, Koven W, Sklan D \& Tandler A (2003) The effect of dietary phosphatidylcholine on the assimilation and distribution of ingested free oleic acid (18:1n-9) in gilthead seabream (Sparus aurata) larvae. Aquaculture 217, 577-588.

Hoehne K (1999) Lipid digestive enzymes in developing larvae of the Atlantic cod (Gadus morhua) and turbot (Scophthalmus maximus). PhD Thesis, University of Karlsruhe.

Howell BR \& Tzoumas TS (1991) The nutritional value of Artemia nauplii for larval sole, Solea solea (L.), with respect to their (n-3) HUFA content. In Proceedings of the Fish and Crustacean Larviculture Symposium, Larvi'91, pp. 63-65 [P Lavens, P Sorgeloos, E Jaspers and F Ollevier, editors]. European Aquaculture Society Special Publication, vol. 15. Gent, Belgium: European Aquaculture Society.

Izquierdo MS, Socorro J, Arantzamendi L \& Hernández-Cruz CM (2000) Recent advances in lipid nutrition in fish larvae. Fish Physiol Biochem 22, 97-107.

Johnsen RI, Grahl-Nielsen O \& Roem A (2000) Relative absorption of fatty acids by Atlantic salmon Salmo salar from different diets, as evaluated by multivariate statistics. Aquacult Nutr 6, 255-261.

Kjørsvik E, Olsen Y, Rosenlund G \& Vadstein O (1991) Effect of various lipid enrichments in rotifers and the development of early stages in turbot. In Proceedings of the Fish and Crustacean Larviculture Symposium, Larvi'91, pp. 20-22 [P Lavens, P Sorgeloos, E Jaspers and F Ollevier, editors]. European Aquaculture Society Special Publication, vol. 15. Gent, Belgium: European Aquaculture Society.

Koven WM, Henderson RJ \& Sargent JR (1994) Lipid digestion in turbot (Scophthalmus maximus). I: Lipid class and fatty acid composition of digesta from different segments of the digestive tract. Fish Physiol Biochem 13, 69-79.

Lie $\varnothing$, Lied E \& Lambertsen G (1987) Lipid digestion in cod (Gadus morhua). Comp Biochem Physiol 88B, 697-700.

Mansbach CM \& Dowell R (2000) Effect of increasing lipid loads on the ability of the endoplasmatic reticulum to transport lipid to the Golgi. $J$ Lipid Res 41, 605-612.

Morais S, Narciso L, Dores E \& Pousão-Ferreira P (2004) Lipid enrichment for Senegal sole (Solea senegalensis) larvae: effect on larval growth, survival and fatty acid profile. Aquacult Int 12, 281-298.

Mourente G \& Vásquez R (1996) Changes in the content of total lipid, lipid classes and their fatty acids of developing eggs and unfed larvae of the Senegal sole, Solea senegalensis Kaup. Fish Physiol Biochem 15, 221-235.

Noaillac-Depeyre J \& Gas N (1974) Fat absorption by the enterocytes of the carp (Cyprinus carpio L.). Cell Tissue Res 155, 353-365.

Nordskog BK, Phan CT, Nutting DF \& Tso P (2001) An examination of the factors affecting intestinal lymphatic transport of dietary lipids. $A d v$ Drug Deliver Rev 50, 21-44.

Ockner RK, Pittman JP \& Yager JL (1972) Differences in the intestinal absorption of saturated and unsaturated long chain fatty acids. Gastroenterology 62, 981-992.

Olsen RE, Henderson RJ \& Ringø E (1998) The digestion and selective absorption of dietary fatty acids in Arctic charr, Salvelinus alpinus. Aquacult Nutr 4, 13-21.

Olsen RE, Myklebust R, Kaino T \& Ringø E (1999) Lipid digestibility and ultrastructural changes in the enterocytes of Artic char (Salvelinus alpinus L.) fed linseed oil and soybean lecithin. Fish Physiol Biochem 21, 35-44.
Olsen AI, Attramadal Y, Reitan KI \& Olsen Y (2000) Food selection and digestion characteristics of Atlantic halibut (Hippoglossus hippoglossus) larvae fed cultivated prey organisms. Aquaculture 181, 293-310.

Patton JS, Warner TG \& Benson AA (1977) Partial characterization of the bile salt-dependent triacylglycerol lipase from the leopard shark pancreas. Biochim Biophys Acta 486, 322-330.

Pérez JA, Rodríguez C \& Henderson RJ (1999) The uptake and esterification of radiolabelled fatty acids by enterocytes isolated from rainbow trout (Oncorhynchus mykiss). Fish Physiol Biochem 20, $125-134$

Poirier H, Mathieu Y, Besnard P \& Bernard A (1997) Intestinal lipid esterification and aging in mice and rats. Comp Biochem Physiol 116, 253-260.

Pousão-Ferreira P, Morais S, Dores E \& Narciso L (1999) Eggs of gilthead seabream Sparus aurata L. as a potential enrichment product of Brachionus sp. in the larval rearing of gilthead seabream Sparus aurata L. Aquacult Res 30, 751-758.

Rainuzzo JR, Reitan KI \& Olsen Y (1994) Effect of short- and long-term lipid enrichment on total lipids, lipid class and fatty acid composition in rotifers. Aquacult Int 2, 19-32.

Rønnestad I, Rojas-García CR, Tonheim SK \& Conceição LEC (2001) In vivo studies of digestion and nutrient assimilation in marine fish larvae. Aquaculture 201, 161-175.

Røsjø C, Nordrum S, Olli JJ, Krogdahl Å, Ruyter B \& Holm H (2000) Lipid digestibility and metabolism in Atlantic salmon (Salmo salar) fed medium-chain triglycerides. Aquaculture 190, 65-76.

Rutter WJ (1967) Protein determinations in embryos. In Methods in Developmental Biology, pp. 671-684 [FH Wilt and NK Wessels, editors]. New York: Academic Press.

Salhi M, Hernández-Cruz CM, Bessonart M, Izquierdo MS \& FernándezPalacios H (1999) Effect of different dietary polar lipid levels and different $n$-3 HUFA content in polar lipids on gut and liver histological structure of gilthead seabream (Sparus aurata) larvae. Aquaculture 179, $253-263$.

Sargent J, Henderson RJ \& Tocher DR (1989) The lipids. In Fish Nutrition [JE Halver, editor]. London: Academic Press.

Sargent JR, McEvoy LA \& Bell JG (1997) Requirements, presentation and sources of polyunsaturated fatty acids in marine fish larval feeds. Aquaculture 155, 117-128.

Sargent JR, McEvoy LA, Estevez A, Bell G, Bell M, Henderson J \& Tocher D (1999) Lipid nutrition of marine fish during early development: current status and future directions. Aquaculture 179, 217-229.

Sigurgisladottir S, Lall SP, Parrish CC \& Ackman RG (1992) Cholestane as a digestibility marker in the absorption of polyunsaturated fatty acid ethyl esters in Atlantic salmon. Lipids 27, 418-424.

Sire M-F \& Vernier J-M (1981) Étude ultrastructurale de la synthèse de chylomicrons au cours de l'absorption intestinale des lipides chez la Truite. Influence de la nature des acides gras ingérés. Biol Cell 40, 47-62.

Van Stappen G (1996) Use of cysts. In Manual on the Production and Use of Live Food for Aquaculture, pp. 107-136 [P Lavens and P Sorgeloos, editors]. Fisheries Technical Paper no. 361. Rome: Food and Agriculture Organization.

Vásquez R, González S, Rodríguez A \& Mourente G (1994) Biochemical composition and fatty acid content of fertilized eggs, yolk sac stage larvae and first-feeding larvae of the Senegal sole (Solea senegalensis Kaup). Aquaculture 119, 273-286.

Watanabe T, Kitajima C \& Fujita S (1983) Nutritional values of live organisms used in Japan for mass propagation of fish: a review. Aquaculture 34, 115-143.

Zar JH (1996) Biostatistical Analysis. Engelwood Cliffs, NJ: Prentice Hall International. 